\title{
Evaluating Indices That Measure Departure of Current Landscape Composition from Historical Conditions
}

Robert E. Keane, Lisa Holsinger, and Russell A. Parsons

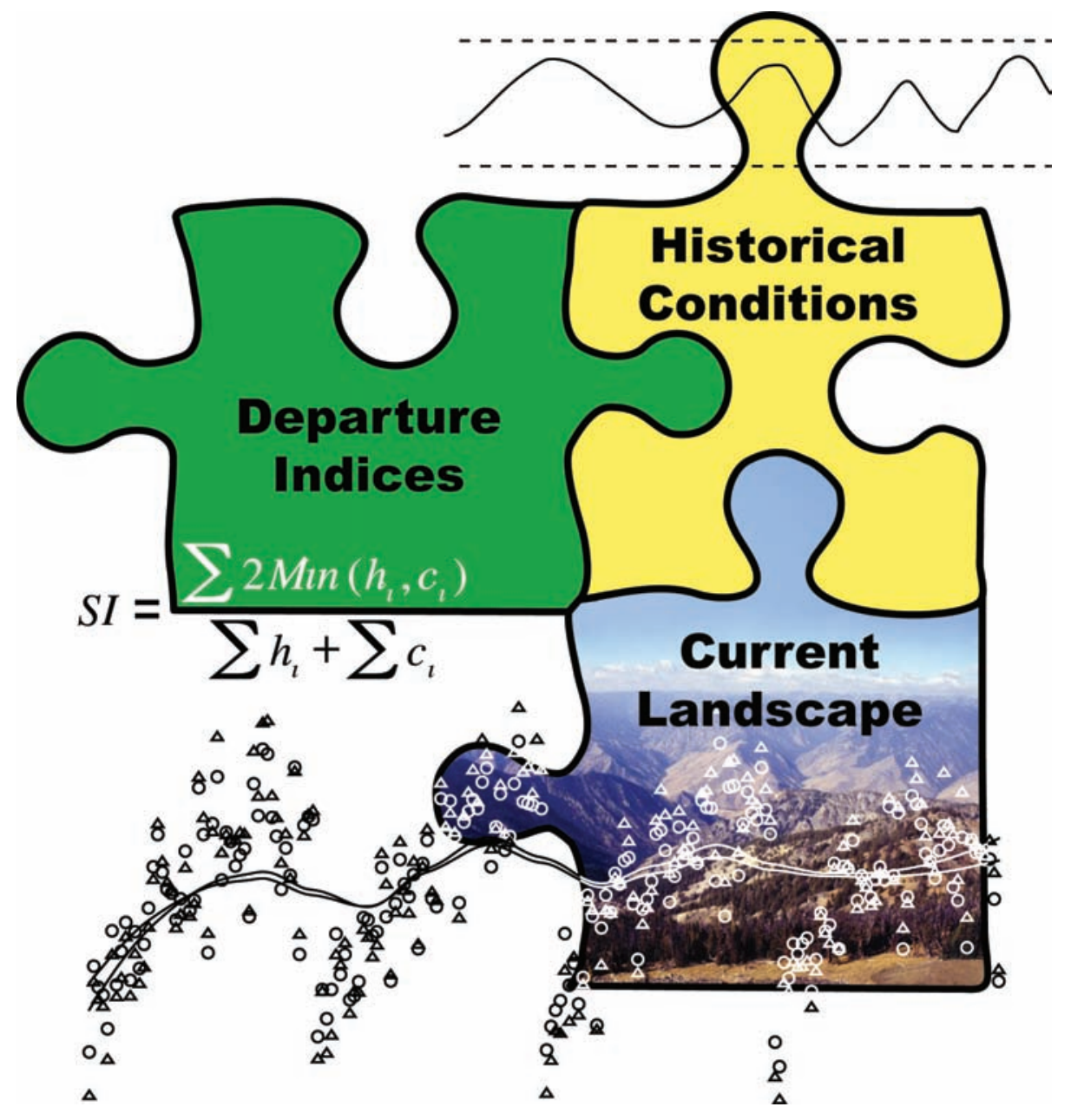

USDA United States Department of Agriculture / Forest Service Rocky Mountain Research Station

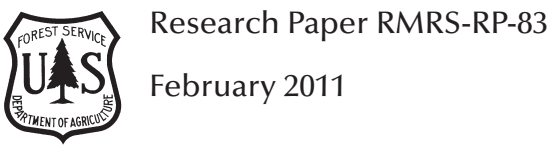


Keane, Robert E; Holsinger, Lisa; Parsons, Russell A. 2011. Evaluating indices that measure departure of current landscape composition from historical conditions. Res. Pap. RMRSRP-83. Fort Collins, CO: U.S. Department of Agriculture, Forest Service, Rocky Mountain Research Station. 19 p.

\section{Abstract}

A measure of the degree of departure of a landscape from its range of historical conditions can provide a means for prioritizing and planning areas for restoration treatments. There are few statistics or indices that provide a quantitative context for measuring departure across landscapes. This study evaluated a set of five similarity indices commonly used in vegetation community ecology (Sorenson's Index, Chord Distance, Morisita's Index, Euclidean Distance, and Similarity Ratio) for application in estimating landscape departure (where departure $=1-$ similarity). This involved comparing composition (vegetation type by area) of a set of reference landscapes to the compositions of 1,000 simulated historical landscapes. Stochastic simulation modeling was used to create a diverse set of synthetic reference and historical landscapes for departure index evaluation. Five reference landscapes were created to represent various degrees of expected departure from historical conditions. Both reference and historical landscapes were created to contain four important factors that could potentially influence departure calculation: (1) number of classes defining landscape composition, (2) dominance of the classes, (3) variability of area with the classes, and (4) temporal autocorrelation. We found that most evaluated indices are useful but not optimal for calculating departure. The Sorenson's Index appeared to perform the best with consistent and precise behavior across the ranges of the four treatments. The number of classes used to describe vegetation had the strongest influence on index performance; landscape composition defined by few classes had the least accurate, most imprecise, and most highly variable departure estimates. While results from this study show the utility of similarity indices in evaluating departure, it is also evident that a new set of statistics are needed to provide a more comprehensive analysis of departure for future applications.

Keywords: ecosystem management, similarity indices, landscape ecology, historical ecology, historical range and variability, HRV, neutral landscapes

\section{Acknowledgments}

This project was supported, in part, by funding from USDA Forest Service Fire and Aviation Management Fire Modeling Institute and the LANDFIRE prototype project. We thank Issac Grenfell for his assistance in programming key statistical algorithms and two anonymous reviewers for their comments.

You may order additional copies of this publication by sending your mailing information in label form through one of the following media.

Please specify the publication title and number.

\section{Publishing Services}

Telephone (970) 498-1392

FAX (970) 498-1122

E-mail rschneider@fs.fed.us

Web site http://www.fs.fed.us/rmrs

Mailing Address Publications Distribution

Rocky Mountain Research Station

240 West Prospect Road

Fort Collins, CO 80526 


\section{Research Summary}

The relatively new concept of Historical Range and Variability (HRV) provides a spatial and temporal foundation for developing benchmark conditions for evaluating difference in today's landscape, and HRV also brings an understanding of past spatial and temporal ecological variability into ecosystem management. However, an important limitation in the application of HRV is the lack of comprehensive analysis techniques to compare the multi-observational historical time series landscape data with the one observation of contemporary conditions. A comprehensive measure is needed for computing departure of current landscape conditions from the historical conditions.

The objective of this study was to evaluate a set of five similarity indices commonly used in vegetation community ecology (Sorenson's Index, Chord Distance, Morisita's Index, Euclidean Distance, and Similarity Ratio) for application in estimating landscape departure. This involved comparing landscape composition (vegetation type by area) of reference landscapes that represents current conditions to the compositions of 1,000 simulated historical neutral landscapes. Stochastic simulation modeling was used to create a diverse set of synthetic reference and historical landscapes for departure index evaluation. Five reference landscapes were created to represent various degrees of expected departure from historical conditions. Both reference and historical landscapes were created to reflect four important factors that may potentially influence departure calculation: (1) number of classes defining landscape composition, (2) dominance of the classes, (3) variability of area with the classes, and (4) temporal autocorrelation.

We found that:

- Most similarity indices are useful but not optimal for calculating departure.

- The Sorenson's Index appeared to perform the best for HRV comparisons with consistent and precise behavior across the ranges of the four treatments.

- The number of classes had the strongest influence on performance of most indices with landscapes that were described by few vegetation classes had the least accurate, most imprecise, and most highly variable departure estimates.

- Temporal autocorrelation had the least effect on the behavior of the departure index.

Results from this study show that similarity indices, especially Sorensen's Index, can be used to evaluate departure, but it is also evident that a new set of statistics are needed to provide a more comprehensive analysis of departure for future applications. 



\section{Contents}

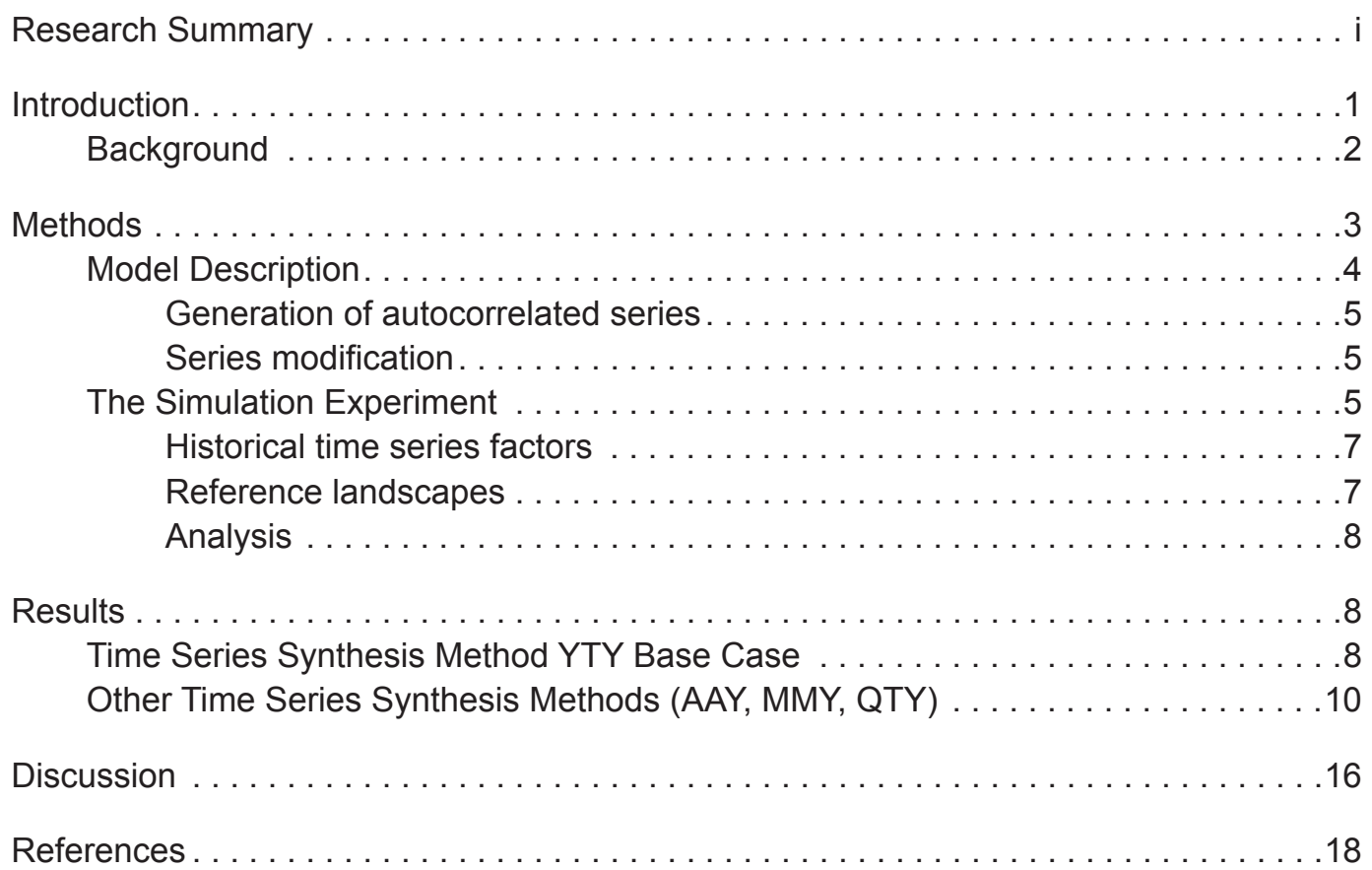





\title{
Evaluating Indices That Measure Departure of Current Landscape Composition from Historical Conditions
}

\author{
Robert E. Keane, Lisa Holsinger, and Russell A. Parsons
}

\section{Introduction}

The era of ecosystem management ushered in the concept that land should be managed as a whole by considering all organisms, and their pattern, abundance, and connectivity of their habitats, and the ecological processes that influence these organisms on the landscape (Bourgeron and Jensen 1994; Crow and Gustafson 1997; Kaufmann and others 1994). But, to effectively plan, design, and implement ecosystem management treatments, managers required benchmarks or reference conditions to fully represent functional ecosystems or landscapes (Cissel and others 1994; Laughlin and others 2004; Swanson and others 1994). Today's landscape conditions can be evaluated against benchmark conditions to determine status, detect change, and design effective treatments to provide society with sustainable and valuable resources while also returning declining ecosystems to a more healthy and resilient condition (Egan and Howell 2001; Hessburg and others 1999; Swetnam and others 1999). It is also critical that these benchmark conditions represent the dynamic character of ecosystems and landscape as they vary over time and space (Morgan and others 1994; Swanson and others 1994).

The relatively new concept of Historical Range and Variability (HRV) was introduced to provide a spatial and temporal foundation for developing benchmark conditions and to bring understanding of past spatial and temporal ecological variability into ecosystem management (Landres and others 1999; Swetnam and others 1999). HRV can be used to plan and implement possible treatments to improve ecosystem health and integrity by assuming that recent historical variation represents the broad envelope of conditions that supports resilient and self-organizing landscapes (Harrod and others 1999; Hessburg and others 1999). One major use of HRV in land management involves comparing a time series of historical landscape conditions (benchmark) to the current landscape condition to detect change and trend (Keane and others 2009). While easily understood, the concept of HRV can be difficult to implement due to scale, data, and analysis limitations (Keane and others 2009; Wong and Iverson 2004). Another important limitation in the application of HRV is the lack of comprehensive analysis techniques to compare the multi-observational historical time series landscape data with the one observation of contemporary landscape conditions (Keane and others 2009; Steele and others 2006).

There are few statistical or ecological analysis techniques that perform well across the temporal and spatial scales of most HRV landscape analyses (Landres and others 1999). Many HRV studies compare landscape composition (vegetation type by area) using indices of departure that are comparable to the similarity indices commonly employed in community ecology to qualitatively evaluate differences in species composition across sample plots (Huhta 1979; Mueller-Dombois and Ellenberg 1974; Wolda 1981). Similarity is often computed as an index or number between zero (dissimilar) and one (identical), and in this paper, we define the converse of similarity as departure (in other words, departure $=1-$ similarity). Sorenson's index, for example, was used by Hann (2004) as a measure to compute landscape departure and fire regime condition class and by Keane and others (2008) to determine changes in landscape composition HRV caused by climate change. Holsinger and others (2006) used a variation of the Sorenson's index to compute departure for the LANDFIRE project. Alternatively, Steele and others (2006) used a statistical regression technique to compute a landscape departure measure with a test of significance, but this measure did not perform well across large regions because the range of departure statistics was quite small making it difficult to identify subtle differences.

Community ecology-based indices of departure have been used for HRV analyses, but several problems have 
been encountered. Keane and others (2008) found that departure measures based on similarity indices are highly influenced by the number of classes used to describe landscape composition, and they are insensitive to subtle, yet important, changes in landscape composition. Major landscape changes can occur, but important disturbance effects were offset by successional changes over space, thereby resulting in minor changes in the departure statistic. Moreover, there are ranges of the departure index (close to zero and one) that are rarely encountered. The inherent variability of classes in the time series, along with their temporal autocorrelation (degree to which previous landscape conditions influence future landscape conditions), can also influence the comparison of departure measures.

The challenge, then, is to identify a comprehensive measure for computing departure of current landscape conditions from the historical time series of past conditions. This measure should perform well regardless of how many mapping units (landscape classes) are used, how the area is distributed across these classes, and how correlated these classes are across time and space. This is complicated by the fact that land managers desire simple measures that are easy to calculate, understand, and interpret, yet are still scientifically credible for describing departure from historical conditions (Hann 2004). The objectives of this study were to evaluate the performance of the community ecology similarity indices for computing departure from historical conditions and to examine how these metrics are influenced by various landscape characteristics. Ultimately, the goal of this study was to determine an optimum measure of departure that can be used in HRV applications for mapping departure across large regions (Steele and others 2006). This study did not attempt to develop new departure indices; instead, it evaluated existing similarity measures developed in the field of community ecology (Mueller-Dombois and Ellenberg 1974; Wolda 1981). Because of this, the findings from this study could also be applied to vegetation classification and community similarity analysis.

\section{Background}

In this study, the landscape is an area of any size or resolution that is composed of unique areas of homogeneous ecological conditions. Each unique area is assigned a class or category that describes a compositional characteristic that is usually specific to the objective of the landscape mapping effort. The class often represents a species dominance classification category, such as a cover type. Landscape composition is the area or percent area covered by each class across the landscape. HRV analysis involves the comparison of one observation of the landscape composition (area by class) for the current landscape with the historical landscape time series represented by numerous sequential observations of historical landscape compositions (fig. 1). In this study, we refer to the reference landscape as a landscape that represents current conditions, but we have altered these current conditions to represent various degrees of departure. Departure is calculated by comparing the areas occupied by the landscape composition classes common to both the reference landscape averaged across all the instances in the historical landscape time series. The term departure index refers to the metric used to calculate departure from historical and it is typically the opposite of similarity.

Many types of similarity indices are used in community ecological analyses with mixed success (Bloom 1981; Faith and others 1987; Kobayashi 1987; Mueller-Dombois

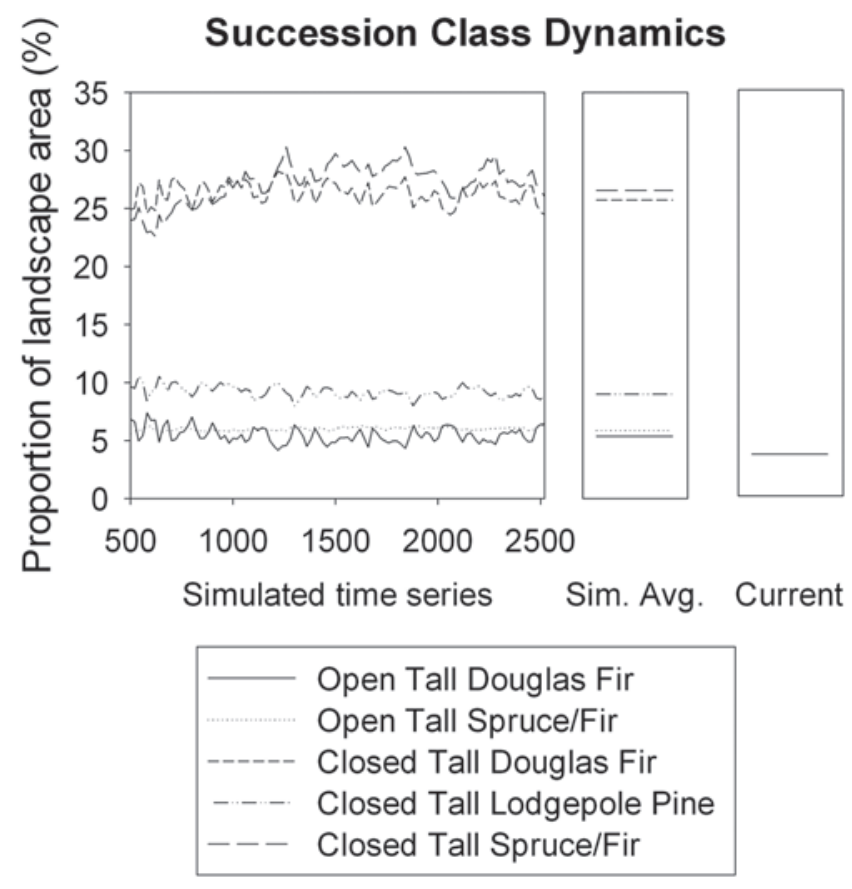

Figure 1-An illustration of the HRV for landscape composition for a 50,000 ha landscape in southwestern Montana (Keane and others 2008) showing an example of the historical range of landscape composition on a Montana USA landscape using five cover types, the average proportion area occupied by each of the five types over the simulation run, and the composition of the current landscape, which contains only open tall Douglas-fir. 
and Ellenberg 1974; Orloci 1967). We assessed a number of common similarity indices (see "Methods" section) and selected five commonly used ecological indices to evaluate in this study. These indices have been used in many vegetation classification and plant diversity studies (Gauch 1982; Ghent 1963; Wolda 1981):

1. Sorenson's Index (SI) is calculated using the following formula:

$$
S I=\frac{\sum 2 \operatorname{Min}\left(h_{i}, c_{i}\right)}{\sum h_{i}+\sum c_{i}}
$$

where $h_{\mathrm{i}}$ refers to the area $\left(\mathrm{m}^{2}\right)$ of the historical reference class within the landscape, $c_{i}$ is the area $\left(\mathrm{m}^{2}\right)$ of the same class on the current landscape, $i$ is class index number, and Min is a function that picks the minimum of two values. Since SI is an index of similarity, it was inversed as SI $=1-$ SI to obtain departure.

2. Morisita's Index (MI) is modified from Horn (1966) and is calculated with the following formula:

$$
M I=\frac{2 \sum\left(h_{i}\right)\left(c_{i}\right)}{\sum h_{i}{ }^{2}+\sum c_{i}{ }^{2}}
$$

where $h_{i}$ refers to the area $\left(\mathrm{m}^{2}\right)$ of the historical reference class $i$ within the landscape, $c_{i}$ is the area $\left(\mathrm{m}^{2}\right)$ of the same class on the current landscape, and $i$ is class index number. Again, MI is actually an index of similarity so it was inversed as MI $=1-\mathrm{MI}$ to obtain the MI departure index.

3. Similarity Ratio (SR) emphasizes the differences using the square of the products in the following formula:

$$
S R=\frac{\sum h_{i} c_{i}}{\sum h_{i}{ }^{2}+\sum c_{i}{ }^{2}-\sum h_{i} c_{i}}
$$

where $h_{i} c_{i}$ is the product of the areas of the historical and current landscape for class $i$. Again, we subtracted the SR from 1.0 to get a departure.

4. Chord Distance (CD) is calculated with the following formula from Faith and others (1987):

$$
C D=\sqrt{\sum_{i=1}^{s}\left(\frac{h_{i}}{\sqrt{\sum_{j=1}^{s} h_{i j}^{2}}}-\frac{c_{i}}{\sqrt{\sum_{k=1}^{s} c_{i k}^{2}}}\right)^{2}}
$$

where $i, j, k$ are the class index numbers. We rescaled the $\mathrm{CD}$ range from zero to $\sqrt{2}$ to zero to 1.0 , and then subtracted from 1.0 to get departure.

5. Euclidean Distance (ED) is much like the SR using the squares of the historical and current landscape areas but the index emphasizes the differences between the two areas as taken from Ludwig and Reynolds (1988):

$$
E D=\frac{\sum\left(h_{i}-c_{i}\right)^{2}}{\sum h_{i}{ }^{2}+\sum c_{i}{ }^{2}}
$$

This paper deals only with departure in landscape composition (area by landscape class) at the landscape level, but it is important to mention that departure can be calculated for many attributes across many scales. Landscape structural attributes, such as contagion, patch density, and largest patch index, can also be used as the response variables to determine departure. It is also possible to determine departure for stand attributes such as basal area, tree density, and timber volume. However, this paper deals only with landscape composition because it is used most by managers (Hann 2004; Keane and others 2006) and it is a complex landscape attribute composed of many descriptor variables (area by class) whose values all sum to the area of the landscape.

\section{Methods}

We explored the suitability of the above measures for evaluating departure using simulation modeling where synthetic historical time series and synthetic reference conditions were created for a partially nested factorial statistical design using a model we built called TSG (Time Series Generator) (fig. 2). In summary, the TSG model created the historical time series of 1,000 landscapes and it also created the set of five reference conditions each with four unique characteristics that were considered factors in our simulation experimental design: (1) number classes, (2) dominance distribution, (3) class variability, and (4) autocorrelation. The five synthetic reference landscapes were designed to represent increasing degrees of departure (expressed as a delta statistic) from the historical time series. We stochastically created an historical landscape time series of 100 landscapes and then replicated this process ten times to obtain 1,000 observations (historical landscapes). We also reduced the historical time series into a simplified set of maps using three synthesis techniques. Since the area of the landscape remains constant over time, we relativized all class areas to sum to 1.0. It is important to note that the 


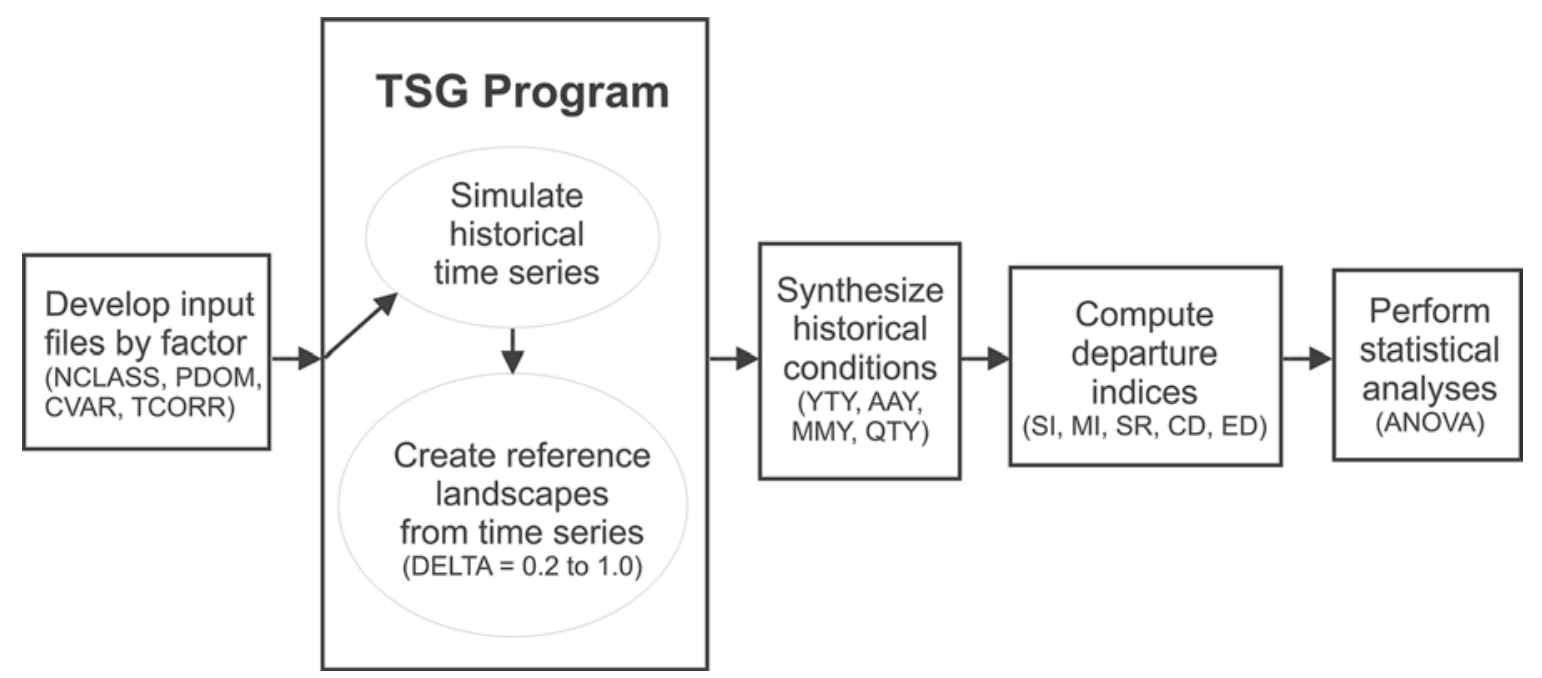

Figure 2-Tasks involved in this simulation experiment where synthetic historical time series are created using five factors using the TSG model and compared against a set of four reference conditions that represent degrees of departure from historical conditions. Five departure indices are used to perform the comparison. The behavior of these departure indices are evaluated across all factors and reference conditions. See table 1 for symbol definitions and simulation details.

historical time series really doesn't represent historical conditions; we used stochastic simulation models to create neutral landscapes with the properties that we wish to evaluate (factors in our experimental design). We named them "historical time series" to be consistent with terminology in HRV analysis, but these are not historical landscapes.

\section{Model Description}

The TSG model was designed to stochastically generate landscape composition time series with known statistical properties to facilitate objective comparison and evaluation of different measures of departure. Our modeling approach reflects a set of design criteria emphasizing simplicity, flexibility, and computational feasibility. Landscape compositional time series may extend for centuries or millennia, and may exhibit temporal autocorrelation over various time scales. Depending on the detail with which the land scape composition is described, the number of vegetation classes over time may range from few to many. In real ecological systems, classes of vegetation may interact over time and space with a diversity of biophysical factors (e.g., climate, disturbance, soils) to create complex landscapes. To explicitly model these interactions mathematically would have required an extensive mechanistic process modeling, requiring a large number of inputs and computational resources. As our purpose was to compare the various measures of departure across a wide spectrum of straightforward comparison cases, we decided to simulate the landscape composition time series as a set of independent series and then assemble them into synthetic landscape time series.

Each simulated landscape composition time series is described by (1) a series length (total number of years for which time series are to be generated), (2) lag length (maximum length in time over which lagged correlations will be considered), and (3) number of classes that represent vegetation states. These three factors were selected based on the results of a previous study in landscape departure (Keane and others 2008). For each class, we specified three parameters, which, when used together, provided a great deal of flexibility and allowed for the generation of a wide range of landscape composition time series across classes. The first parameter, TCORR or temporal correlation, controls the temporal autocorrelation within the series for a class and is described by an $\mathrm{ACF}$ (AutoCorrelation Factor) value that ranges from zero (no autocorrelation) to one (highly correlated in time). The second parameter, PDOM or percent dominant, sets the target dominance, or the degree to which a landscape is dominated by a few classes. PDOM is defined as the expected mean proportion of total landscape area occupied by a given class over the length of 
the time series. Since these are proportions, the sum of the PDOM parameter values across all classes for a given simulated landscape composition time series must be equal to 1.0. The third parameter, CVAR or class variation controls the amount of variability in the time series for that class and it is scaled from 0.3 to 1.2 in this study based on analyses of other mapped landscapes.

The simulation of a landscape composition time series consists of two steps: (1) the generation of autocorrelated series creates independent autocorrelated time series for each class and (2) the series modification that rescales those independent classes to conform to the PDOM and CVAR parameters, and relativizes all classes such that they represent proportions of total landscape area by class for each point in time.

Generation of autocorrelated series-For each class, an independent, stationary, autocorrelated time series is generated using the ACF parameter. The ACF parameter sets the slope of a simple exponential decay function of the form:

$$
r(t)=e^{(-\lambda t)}
$$

where $r(t)$ is the correlation coefficient between the value at a given point and the value at lag time $t$, and $\lambda$ is the ACF parameter. This exponential decay function represents the coefficients of a theoretical autocorrelation function (ACF). Higher values of ACF result in a lower correlation, while lower values maintain correlation over a longer period of time. This theoretical autocorrelation function is then used to generate an autoregressive series of the specified length following a process that has been used extensively since the late 1960s (Box and Jenkins 1990). Given an autocorrelation function $\rho(k)=\rho_{k}$ for $\mathrm{k}=1, \ldots, \mathrm{m}$, an autoregression function can be obtained in the following way:

$$
\text { Let } P_{m}=\left(\begin{array}{ccccc}
1 & \rho_{1} & . . & . . & \rho_{m-1} \\
\rho_{1} & 1 & \rho_{1} & . . & \rho_{m-2} \\
. . & . . & 1 & \rho_{1} & . . \\
. . & . . & . . & 1 & . . \\
\rho_{m-1} & . . & . . & . . & 1
\end{array}\right)
$$

And let $\underline{\rho}_{m}=\left(\begin{array}{c}\rho_{1} \\ . . \\ \rho_{m}\end{array}\right)$

$$
\text { And } \underline{\varphi}_{m}=\left(\begin{array}{c}
\varphi_{1} \\
. . \\
\varphi_{m}
\end{array}\right)
$$

Then the equation

$$
\underline{\varphi}=P_{m}^{-1} \underline{\rho}_{m}
$$

will satisfy the autoregressive process:

$$
\gamma_{0}=\varphi_{1} \gamma_{-1}+\varphi_{2} \gamma_{-2}+. .+\varphi_{p} \gamma_{-p}+\sigma_{a}^{2}
$$

Thus $z_{t}=\varphi_{1} z_{t-1}+\varphi_{2} z_{t-2}+. .+\varphi_{m} z_{t-m}+a_{t}$ where $a_{t}$ is a random shock with variance $\sigma_{a}^{2}$, in which the variance of the output will reflect the character and structure of the autocorrelation function used as input as follows:

$$
\sigma_{a}^{2}=\sigma_{z}^{2} 1-\rho_{1} \varphi_{1}-\rho_{2} \varphi_{2}-. .-\rho_{m} \varphi_{m}
$$

The autocorrelated series for a given vegetation class (Equation 8) is then arranged as a set of linear equations that are solved through a process of Lower-Upper decomposition followed by forward and then backward substitution using standard numerical routines (Press and others 2002).

Series modification-Once all of the independent series of each class have been generated according to the process described above, the series are modified so they can represent landscape composition across all vegetation classes. The values for each series are rescaled to the range $[\mathrm{L}, \mathrm{H}]$, with the following relation:

$$
X_{\text {mod }}=\frac{(X-m)(H-L)}{(M-m)}+L
$$

where $X$ is the unmodified series values, $X_{\text {mod }}$ is the modified series, $m$ is the minimum value of the unmodified series and $M$ is the maximum of the unmodified series, and

$$
\begin{aligned}
& L=D-D V \\
& H=D+D V
\end{aligned}
$$

where $D$ is the PDOM input parameter and $V$ is the CVAR parameter. Finally, each class value for each year is divided by the sum over all classes for that year to ensure that they sum to 100 percent of the total area.

\section{Simulation Experiment}

The goal of this simulation experiment was to compare the behavior of departure indices across a wide range of conditions of historical time series and reference landscapes with known statistical properties to determine if any index is superior and if any of the indices have 
undesirable qualities that may influence the interpretation of HRV departure results (Keane and others 2002, 2008). Initially, we wanted to take an ANOVA (Analysis of Variance) approach and conduct a fully nested factorial experiment using extensive simulations from the TSG model, but preliminary results revealed that, while the departure indices differed across all treatments, the small number of treatments within a factor (less than 5 treatments) did not provide sufficient detail to effectively evaluate the behavior of each index across the full range of possible historical and reference conditions. Therefore, we re-designed our experiment so that a wide range of values (treatments) for each factor were simulated with TSG to determine critical thresholds in departure index behaviors. Because there were so many treatments that spanned the full range of behaviors, it was difficult to simulate all factor-treatment combinations with the TSG model. Therefore, we simulated the range of values for one factor while holding all other factors to a base case (noted in underlined bold in table 1) and then used oneway ANOVA to evaluate differences among treatments by factor.

We also wanted to include a number of other similarity indices in the evaluation, but results from an extensive preliminary analysis revealed that some similarity indices had virtually identical results, while others had obvious undesirable behaviors across a minor subset of the important factors mentioned above. The Jaccard

Table 1-Factors evaluated for testing the response of departure indices to several historic time series and reference conditions. Values in italics and underlined are those held constant while varying a different factor (base condition).

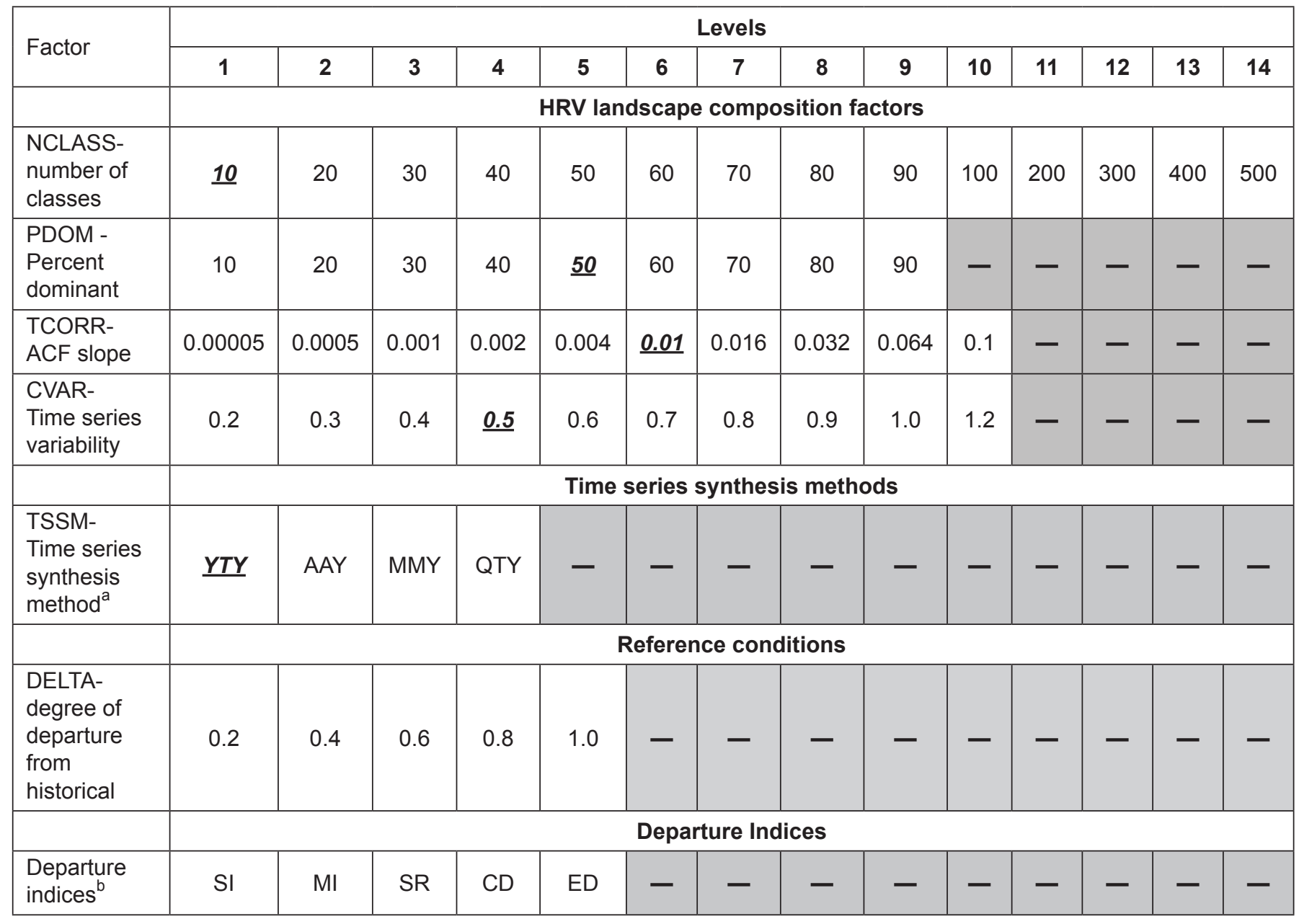

${ }^{a}$ Time series synthesis methods are defined as the comparison of the reference condition to (1) all instances in the historical time series and an average departure is computed (YTY-year to year); (2) one synthetic historical landscape that is the average of all classes across all landscapes in the historical time series (AAY); (3) two historical landscapes that are the minimum and the maximum, respectively, of each class in the historical series (MMY); and (4) one synthetic historical landscape created from the $90 \%$ quantile of class area (QTY).

beparture indices are computed from the following similarity indexes: SI-Sorenson's Index, MI-Morista's Index, SR-Similarity Ratio, CD-Chord Distance, and ED-Euclidean Distance. 
(Mueller-Dombois and Ellenberg 1974) and Gleason (Huhta 1979) indices, for example, performed poorly in nearly all cases, while the FRCC (Hann 2004) index was acceptable, but was highly correlated to the Sorenson's index. Therefore, we reduced the number of indices to the set of five discussed above (table 1).

Historical time series factors-We had previously identified four factors that commonly influence the calculation of current landscape composition departure from historical conditions (table 1) (Keane and others 2008). The number of classes (NCLASS) used to describe the landscape composition (cover types, for example) is influential in departure calculations because major changes in departure are difficult to detect when a large number of classes are used (Keane and others 2008). To test this, we varied the number of classes from 10 to 500 to encompass the full range of possible mapping units that are used to describe landscapes. Percent dominance (PDOM) describes the percent of the number of classes that are dominant in a time series. We define dominant as comprising at least 80 percent of the landscape area. For example, 10 percent dominance for 10 classes would mean that one class comprises 80 percent of the landscape while the remaining 20 percent of the area is spread over the other nine classes.

Class variability (CVAR) was used to explore the effect of the variation within classes on departure calculations. In TSG, the variance depends on the percent dominance (PDOM) value where the PDOM value is multiplied by the CVAR value (in this study $0.2<$ CVAR $<1.2$; table 1) to compute a range around the historical mean (area in a class + PDOM*CVAR*area). Low CVAR values $(<0.5)$ indicate low variability in class fluctuations across sequential landscapes, while high CVAR values $(>0.8)$ represent a significant increase in the noise in the HRV time series. Temporal autocorrelation (TCORR as represented by ACF parameter) is also an important factor because departure may be difficult to detect in landscape time series that are strongly autocorrelated in time. The TSG program uses the ACF (see "Model Description" section) to create time series with low to high degrees of autocorrelation ( 0.0 to 0.3 , respectively). We simulated several landscapes with the LANDSUM landscape simulation model (Keane and others 2006) to identify reasonable ranges of ACF values and found that the simulated time series ACF value ranges from 0.00002 (uncorrelated) to 0.1 (somewhat correlated) (table 1).
We also included another analysis to evaluate the time series synthesis method (TSSM). Historical time series of landscape compositions can be summarized in a number of ways to simplify departure calculations. The most obvious and common method involves no synthesis at all where each landscape in the time series is compared to the reference, and in our simulation experiment, this Year-to-Year (YTY) calculation computes departure by comparing each historical map in the series to the reference map, and then averages all departures across every comparison in the historical time series $(1,000$ comparisons in this study). While the YTY approach is the most intuitive and provides the greatest detail in the HRV analysis, it is sometimes impractical because, in an operational setting, it requires that digital maps for each time step in the historical series be stored for each landscape, requiring extensive disk space. To minimize computer storage, simplify computational demands for large regions, and provide a simple and easy historical reference for managers (Hann 2004), we created three simplified historical time series that may have application in landscape management. An average historical year (AAY) was created by averaging the area for each class across all instances in the historical time series to create one average historical condition to compare with the reference. We also reduced the time series to two instances by taking the minimum area for each class across all years in the series and the maximum area for each class in the series to create two observations in the "time series." We then averaged departure across both the minimum and maximum years (MMY). Last, we took the 90 percentile of class area over all years (QTY) to create one historical year to compare with the reference. This study concentrated on the base case of YTY (average across all historical combinations) for the evaluation analysis, but we also report results on the effectiveness of reducing historical time series.

Reference landscapes-The reference condition in this study represents the condition of the current landscapes in the calculation of departure from HRV. Reference conditions that are highly disparate from the historical time series test the magnitude of departure that the index can capture, while similar reference and historical conditions test the sensitivity of the index. In this study, we created a series of five different reference conditions that spans a range of departure from the set of historical time series conditions (fig. 2). The degree of departure is represented by a parameter called DELTA (a number ranging from 
0 to 1) that describes the proportion of area in a reference landscape class that will be shifted away from the average historical value for that class. A value of 1.0 would mean maximum departure or 100 percent of the area for each reference class is in a different class than the historical time series average. Five reference conditions were created using DELTA values from 0.2 (minimum expected departure) to 1.0 (maximum expected departure) in 0.2 increments (Table 1).

Analysis-The response variables in this analysis are values of the five departure indices (SI, MI, CI, SR, EI) for each of the 10 replicates for the four factors (NCLASS, CVAR, PDOM, TCORR) across all treatment levels per factor, compared to all five reference (DELTA) conditions. We stratified this analysis into two phases. The first phase involved using the TSG program to simulate 1,000 historical landscapes to create the set of ten historical time series. We ran TSG for all treatments within a factor while holding all other factors at the base case (table 1). We then performed ANOVA techniques to detect differences between treatments (NCLASS, PDOM, CVAR, TCORR) but not differences across factors (values of treatments) for only the YTY time series synthesis method (YTY or year to year involves averaging departures computed by comparing a reference condition to each landscape in the ten historical time series). In the second phase, we conducted the same simulations across the remaining time series analysis methods (AAY, MMY, QTY) (fig. 2). Again, ANOVA was used to test differences across treatments.

As mentioned, we used ANOVA techniques to determine significance across treatments within the factors, but index performance was mostly evaluated based on visual inspection of the box and whisker plots of the simulation results using the following criteria:

1. Low and consistent levels of variability across replicates (boxes small and same size).

2. Consistent behavior across the range of factor values; no decreasing or increasing trends.

3. Distance from expected departure. We expected a certain departure value based on the specified DELTA value input for each reference condition, and included this value as a line on all box plot graphs.

4. Similar behavior across all values of DELTA. The properties of the variance across replicates as described in 1 and 2 above should be the same across all departure reference sets.
An ideal index would have low replicate variability (small boxes and whiskers) and the replicate mean would be identical to the expected departure.

\section{Results}

This study illustrated that there is a wide variety of behaviors for all departure indices across all types of historical time series and reference conditions for the YTY time series synthesis technique (other synthesis methods will be discussed in the last part of this section). We first discuss the behavior of departure indices using the averaging synthesis method (YTY) from a qualitative perspective and in the context of a statistical evaluation using ANOVA.

\section{Time Series Synthesis Method YTY Base Case}

The Sorenson's Index (SI) performed well across a wide range of classes (NCLASS) regardless of the degree of departure in the five reference sets (fig. 3a). There was little variability in this index across the full range of number of classes (10-500 classes). However, at low class numbers (10-30), the variability seemed to increase and the ability of the index to detect departure decreased (greater distance from the expected departure line). SI also performed well across most levels of percent dominance (PDOM), except when reference and historical conditions were highly departed (high DELTA) even though there were significant differences across most levels of expected departure (see asterisks in fig. 3b). When DELTA was high (high expected departure), the SI performed well, even when the landscape was dominated by a few classes (10-30\% dominance), but performance decreased as landscape area was evenly distributed across all classes because both variability across replicates (bigger boxes and whiskers) and distance from expected departure increased. SI also seemed unaffected by the inherent variability (CVAR) in the historical time series (fig. 3c). In general, when there was higher departure (DELTA near 1.0), SI was more variable, less precise, and less accurate (distance from expected departure increases); however, when expected departure was low (DELTA $<0.5)$, SI had low variability and consistent behavior across all levels of variability. Temporal autocorrelation (TCORR) appeared to have little effect on SI performance, except maybe when the similarity of reference and historical landscapes was low (DELTA $>0.6$; fig. 3d). 

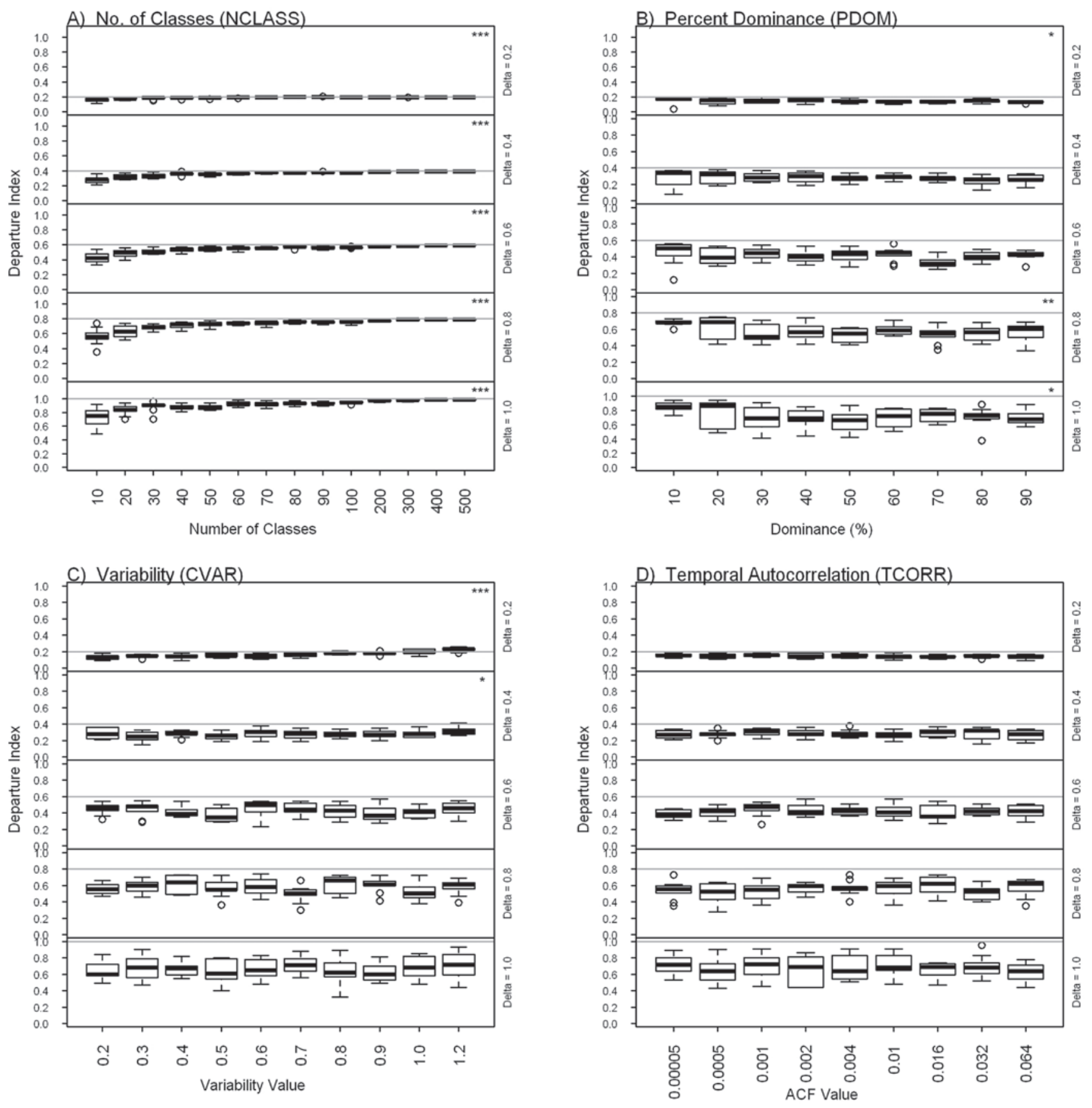

Figure 3-Sorenson's Index (SI) performance as a departure measure. Box and whisker plots of 10 replicates of 100 historical landscapes were compared to five reference landscapes that represent similar $($ DELTA $=0.2)$ to highly departed $(D E L T A=1.0)$ reference conditions. We evaluated four factors: (a) number of classes, (b) percent dominance, (c) variability of classes, and (d) temporal autocorrelation. In the boxplots, the lower boundary of each box is the first quartile (25th percentile), the upper boundary is the third quartile (75th percentile), and the line within the box represents the median of the distribution. The upper and lower whiskers represent the 10th and 90th percentile and the dots below and above the whiskers represent outlying values. Asterisks within each plot indicate significant differences in the Departure Index across all treatments at the $0.05\left(^{*}\right), 0.01\left(^{* *}\right)$, and $0.001\left({ }^{* * *}\right)$ levels. 
The Morisita Index (MI) was quite sensitive to NCLASS with values farther from expected departure when there were fewer classes (less than 30) at high expected departures (DELTA $>0.8$ ), or when there were a high number of classes (greater than 50) at low expected departures (DELTA <0.6) (fig. 4a). As with SI, the differences in MI across all classes were highly significant (three asterisks in fig. 4a). MI seemed completely ineffectual at describing departure as NCLASS increased for reference conditions that were similar to historical conditions. However, MI performed well when expected reference departure was high (DELTA $>0.8$ ) with low replicate variability (except for lowest NCLASS) and consistent behavior across all classes. The level of class dominance (PDOM) in the HRV time series had little effect on MI behavior except at high expected departure reference conditions with high variability across replicates. There was reduced replicate variability and consistent MI behavior across all levels of dominance when expected reference departure reference conditions were low (DELTA <0.2) (fig. $4 \mathrm{~b}$ ). The same findings were true across the levels of class variability (CVAR) with MI values lower than expected and more variable across levels of PDOM and CVAR (fig. 4c). MI behavior seemed consistent across all levels of class variability, but the replicate variability (box and whisker ranges) increased when references were dissimilar to historical conditions (DELTA >0.8). As with SI, temporal autocorrelation did not seem to affect MI results (fig. 4d).

The Similarity Ratio (SR) had a mixed performance across most factors (fig. 5). SR performance was especially poor when the number of classes and the degree of similarity between reference and historical were high (DELTA <0.5). Replicate variability was high and somewhat variable when NCLASS was low (less than 60) and reference-historical landscapes were similar (DELTA <0.4) (fig. 5a). SR appeared to perform well across all levels of PDOM when reference-historical similarity was high, but when expected departure was high (DELTA >0.5), replicate variability was high, distance from expected departure increased, and overall behavior was inconsistent (fig. 5b). Class variability (CVAR) and temporal autocorrelation (TCORR) had the same effect on SR with dissimilar reference-historical comparisons (DELTA >0.5) having greater replicate variability, less accuracy (farther from expected departure line), and less precision (inconsistent behavior) (figs. $5 \mathrm{c}, \mathrm{d}$ ).

Chord Distance (CD) had the same mixed performance as SR for nearly every factor (fig. 6). CD performance was poor when NCLASS was high (>50) and the degree of similarity between reference and historical was great (DELTA $<0.5$ ) because the replicate variability was high and inconsistent, especially when NCLASS was low (<100) (fig. 6a). CD performance was mixed across most levels of PDOM with high replicate variability and imprecise behavior, except when reference-historical similarly was high (DELTA $<0.5$ ), when the CD behavior stabilized and became highly consistent and somewhat accurate (fig. 6b). Class variability (CVAR) effects on CD were strongest when DELTA was high (when reference-to-historical landscapes are dissimilar) with $\mathrm{CD}$ becoming more variable and inconsistent (fig. 6c). Temporal autocorrelation had the least effect on CD with only the least departed landscapes fostering the best $\mathrm{CD}$ behaviors (fig. $6 \mathrm{~d}$ ).

The last index, Euclidean Distance (ED), had only marginally better performance than CD or SR (fig. 7). The effect of the number of classes on ED was especially pronounced when DELTA was low (minimal expected departure from historical conditions) as the distance from expected departure line dramatically increased with increasing number of classes (fig. 7a), but when DELTA was high, ED performed well except when there were a low number of classes $(<10)$. As with the last three indices, the ED behavior is highly inconsistent across the gradient of dominance (PDOM) and class variability (CVAR) with distance from the expected departure line and replicate variance quite variable (figs. $7 b, c)$. Again, temporal autocorrelation didn't seem to affect ED behavior as much as the similarity of the referencehistorical conditions (fig. 7d) with the most consistent ED behavior occurring when expected departures were low.

\section{Other Time Series Synthesis Methods (AAY, MMY, QTY)}

Simplifying the historical time series by comparing one or two historical conditions to one reference condition instead of calculating a departure for each landscape in the historical time series is probably more desirable for land managers, but this may create greater uncertainty and more inaccurate HRV evaluations. In this section, we present results of the remaining time series synthesis methods, but only for the Sorenson's Index (SI) since it performed the best, and only for two reference conditions (highly similar where DELTA $=0.2$ and highly departed where DELTA $=1.0$ ). 

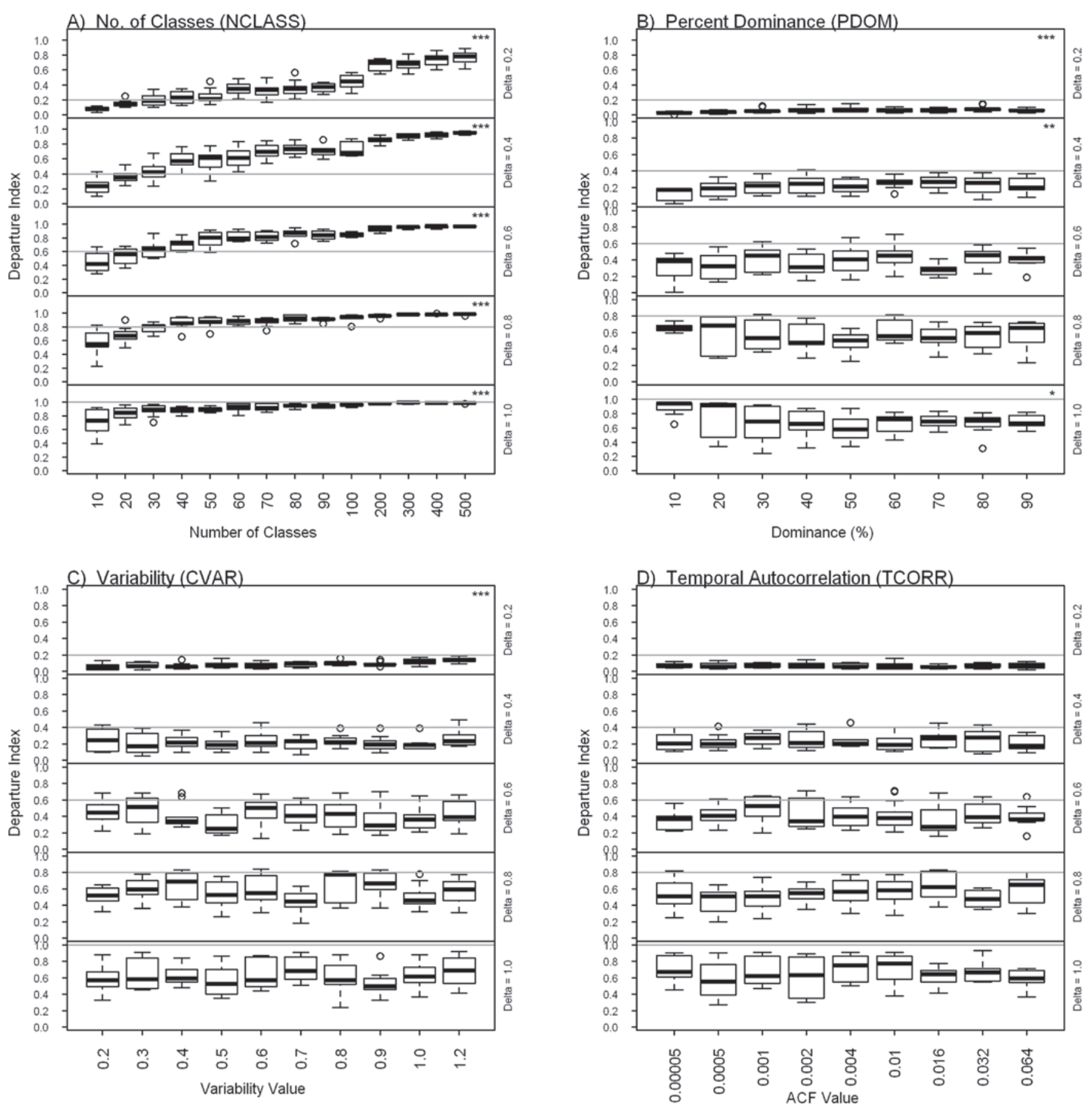

Figure 4-Morista's Index (MI) performance as a departure measure. Box and whisker plots of 10 replicates of 100 historical landscapes were compared to five reference landscapes that represent similar (DELTA $=0.2)$ to highly departed $(D E L T A=1.0)$ reference conditions. We evaluated four factors: (a) number of classes, (b) percent dominance, (c) variability of classes, and (d) temporal autocorrelation. In the boxplots, the lower boundary of each box is the first quartile (25th percentile), the upper boundary is the third quartile (75th percentile), and the line within the box represents the median of the distribution. The upper and lower whiskers represent the 10th and 90th percentile and the dots below and above the whiskers represent outlying values. Asterisks within each plot indicate significant differences in the Departure Index across all treatments at the $0.05\left(^{*}\right), 0.01\left(^{* *}\right)$, and $0.001\left(^{* * *}\right)$ levels. 

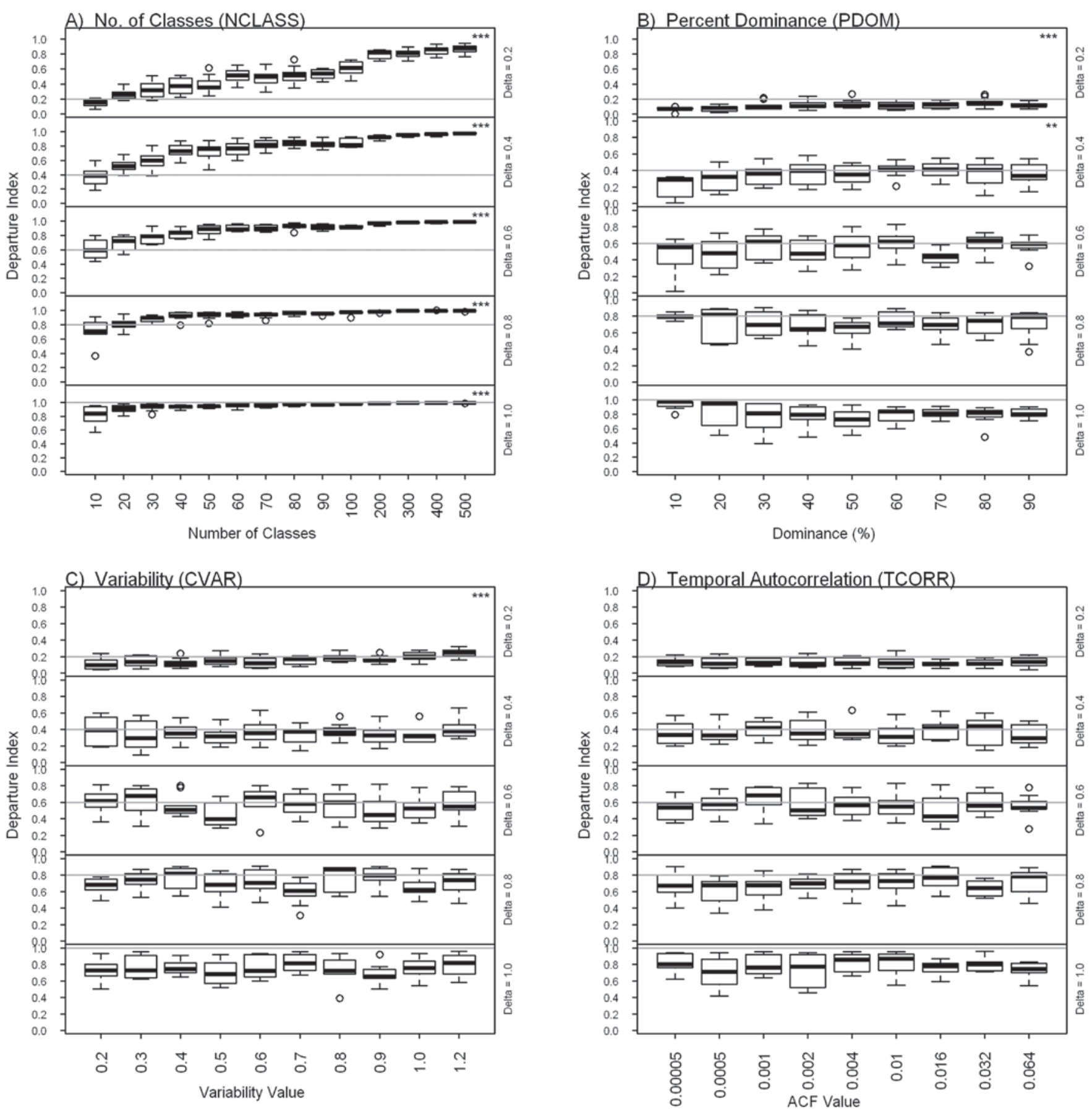

Figure 5-Similarity Ratio (SR) performance as a departure measure. Box and whisker plots of 10 replicates of 100 historical landscapes were compared to five reference landscapes that represent similar $(D E L T A=0.2)$ to highly departed $(D E L T A=1.0)$ reference conditions. We evaluated four factors: (a) number of classes, (b) percent dominance, (c) variability of classes, and (d) temporal autocorrelation. In the boxplots, the lower boundary of each box is the first quartile (25th percentile), the upper boundary is the third quartile (75th percentile), and the line within the box represents the median of the distribution. The upper and lower whiskers represent the 10th and 90th percentile and the dots below and above the whiskers represent outlying values. Asterisks within each plot indicate significant differences in the Departure Index across all treatments at the $0.05\left(^{*}\right), 0.01\left({ }^{* *}\right)$, and $0.001\left({ }^{* * *}\right)$ levels. 

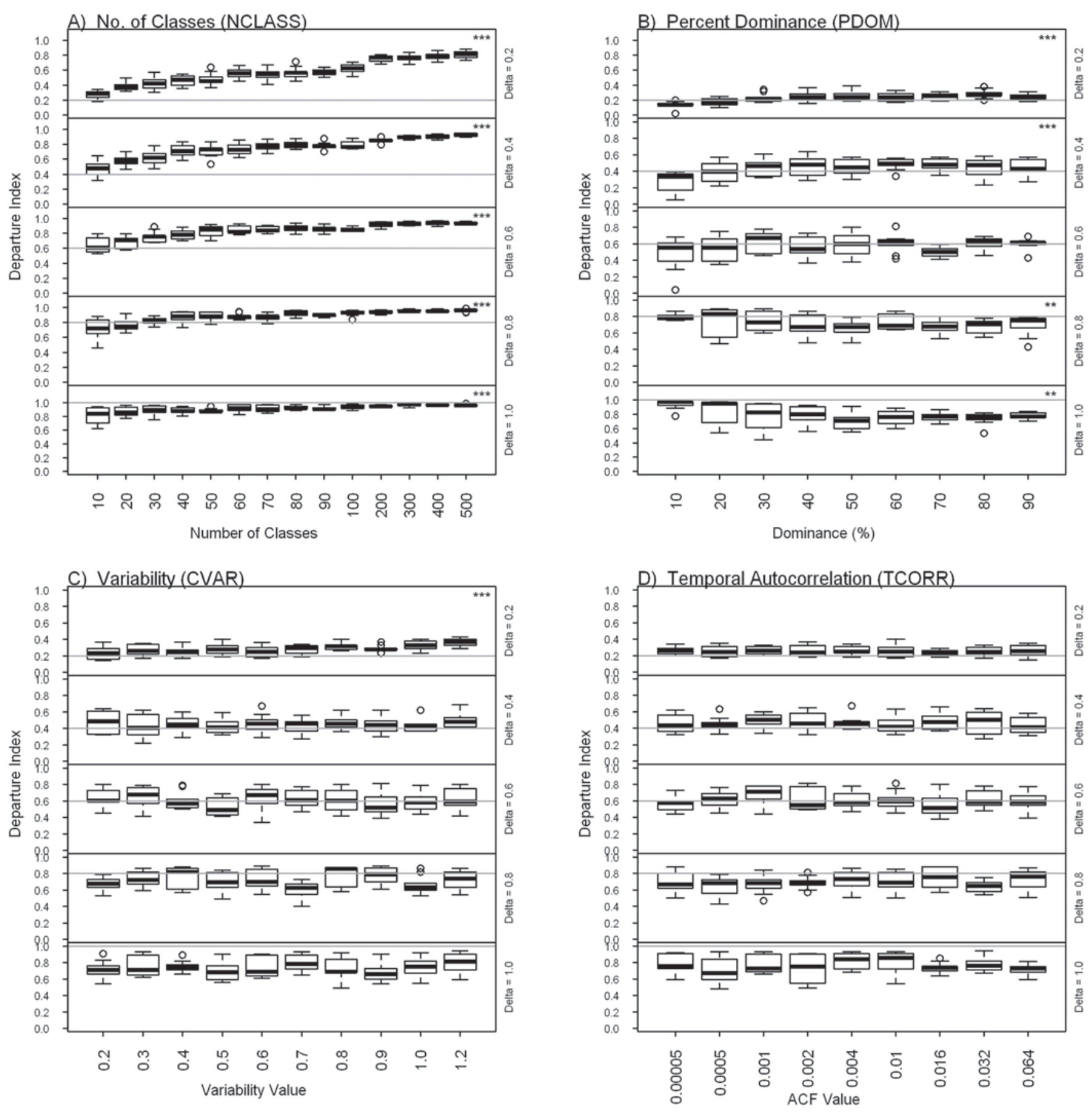

Figure 6-Chord Distance (SR) performance as a departure measure. Box and whisker plots of 10 replicates of 100 historical landscapes were compared to five reference landscapes that represent similar (DELTA $=0.2)$ to highly departed $(D E L T A=1.0)$ reference conditions. We evaluated four factors: (a) number of classes, (b) percent dominance, (c) variability of classes, and (d) temporal autocorrelation. In the boxplots, the lower boundary of each box is the first quartile (25th percentile), the upper boundary is the third quartile (75th percentile), and the line within the box represents the median of the distribution. The upper and lower whiskers represent the 10th and 90th percentile and the dots below and above the whiskers represent outlying values. Asterisks within each plot indicate significant differences in the Departure Index across all treatments at the $0.05\left(^{*}\right), 0.01\left({ }^{* *}\right)$, and $0.001\left({ }^{* * *}\right)$ levels. 

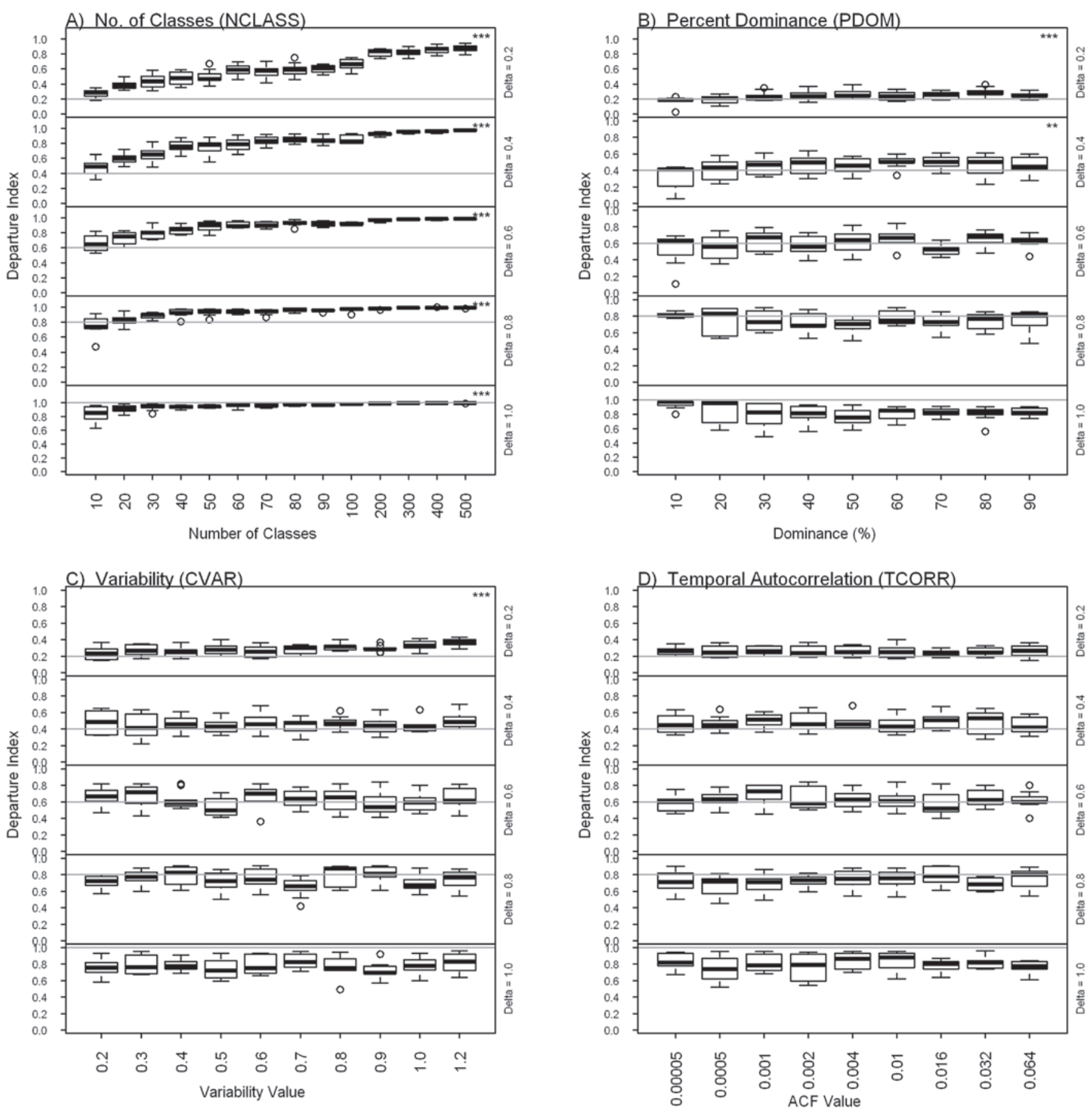

Figure 7-Euclidean Distance (ED) performance as a departure measure. Box and whisker plots of 10 replicates of 100 historical landscapes were compared to five reference landscapes that represent similar $(\mathrm{DELTA}=0.2)$ to highly departed $(\mathrm{DELTA}=$ 1.0) reference conditions. We evaluated four factors: (a) number of classes, (b) percent dominance, (c) variability of classes, and (d) temporal autocorrelation. In the boxplots, the lower boundary of each box is the first quartile (25th percentile), the upper boundary is the third quartile (75th percentile), and the line within the box represents the median of the distribution. The upper and lower whiskers represent the 10th and 90th percentile and the dots below and above the whiskers represent outlying values. Asterisks within each plot indicate significant differences in the Departure Index across all treatments at the $0.05\left({ }^{*}\right), 0.01\left({ }^{* *}\right)$, and $\left.0.001{ }^{* * *}\right)$ levels. 

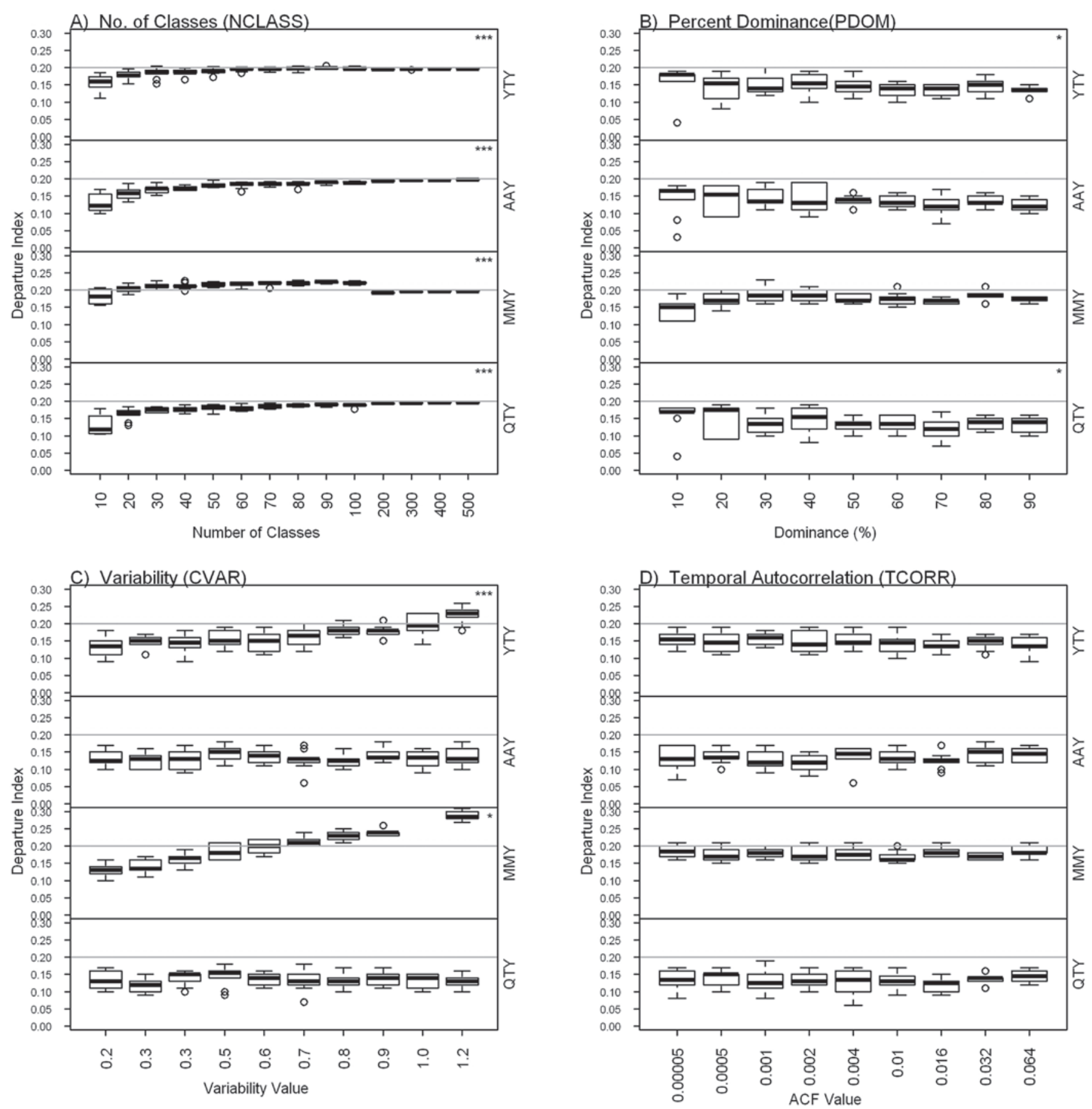

Figure 8-Performance of Sorenson's Index for the four time series synthesis methods when reference landscapes are similar to historical conditions (expected departure low; DELTA = 0.2). Results for the average departure calculation across all years (YTY) is shown in (a) while the time series synthesis methods reduced the 1,000 historical landscapes into three simplified series: (b) average across all years (AAY), (c) a minimum and maximum values across all year, and (d) the $90^{\text {th }}$ percentile value across all years. Box and whisker plots of 10 replicates and the lower boundary of each box is the first quartile (25th percentile), the upper boundary is the third quartile (75th percentile), and the line within the box represents the median of the distribution. The upper and lower whiskers represent the 10th and 90th percentile and the dots below and above the whiskers represent outlying values. Asterisks within each plot indicate significant differences in SI across all treatments at the $0.05\left({ }^{*}\right), 0.01\left({ }^{* *}\right)$, and $0.001\left({ }^{* * *}\right)$ levels. 
In general, the synthesis methods did not affect the behavior of SI across the four factors (fig. 8) for the similar reference-historical conditions (DELTA $=0.2$ ), but the variability across replicates (box size) did decrease. The AAY method (average historical landscape) seemed to have nearly the same result as our detailed base case YTY method. The MMY method was the least desirable with some major shifts in behavior for NCLASS and PDOM. The QTY method seems to yield acceptable results but this method should only be used when degrees of departure must be integrated into the HRV analysis in the context of the stated management objective.

None of the synthesis methods produced acceptable results when the reference landscape was highly departed from the historical representation (DELTA=1.0) (fig. 9). Acceptable behavior occurred for the AAY method when class numbers were high (greater than 50 classes) and percent dominates were low (less than 10 percent; 10 percent landscape classes have 80 percent of the area). All synthesis methods performed poorly across all levels of class variability and temporal autocorrelation with high variability, high expected departure, and inconsistent behaviors (fig. 9).

\section{Discussion}

While most of the vegetation community ecology based departure indices evaluated in this study performed acceptably for determining departure from HRV, none of them seemed to contain the optimum qualities for comprehensive assessments of departure across all possible landscape conditions. Those indices that performed well for one factor (number of classes, for example), performed poorly for other factors (percent dominance, for example). The Sorenson's Index (SI) appeared to perform the best in this study when it was qualitatively compared with the other indices using a qualitative scale of 1 to 5; the SI score is more than 10 above all other indices (table 2). SI was least affected by the four simulated factors but it still had unacceptable behavior when the number of classes was low and the expected departures were high. While many studies have used the Sorenson's Index or some variant with acceptable results (Holsinger and others 2006; Keane and others 2008; Wimberly and others 2000), it appears that the simplest landscapes (low number of classes, few classes dominate, low variability) yield the most suspect results, especially when reference conditions are similar to the historical time series. This is also true for all the other evaluated indices.
The synthesis of an extensive historical time series of landscape maps into simplified historical references (average, minimum-maximum, and $90^{\text {th }}$ percentile) did not create the high degree of uncertainty that we expected (greater replicate variability). Instead, it appears that reducing historical time series could be a viable option for land managers who cannot store or manage large historical data sets. This is especially important as more land managers obtain their HRV time series from simulation modeling (Keane and others 2002; Nonaka and Spies 2005; Wimberly and others 2000) because models can produce extensive outputs of simulated historical conditions. However, these synthesis options could result in less variability in the historical record that may make it difficult to detect subtle changes in the reference landscape. While we advocate that the entire historical time series be used to determine departure, we recognize that the average historical landscape may also be a useful alternative for computing departure.

One situation that was not explored in this study is when classes that did not exist in the historical reference conditions were present in the current conditions or vice versa. Today's landscapes are highly departed from historical conditions partially because of increases in exotic plant communities, which were absent on historical landscapes. This important phenomenon (addition of new classes) could also affect the behavior of similarity indices. A related unevaluated situation is the extinction of an historical class or the absence of a class in the reference landscape (missing classes). The main effect of these additional factors on departure measures may be to increase variability across replicates.

The departure indexes used in this study have many limitations that influence their use and interpretation in HRV landscape analyses. First, these indices only describe the magnitude and trend of change at the landscape level and do not incorporate geographical change in their derivation. Decreases in class area in one portion of the landscape may be offset by increases in that class in another portion resulting in no net change and a stable departure index, yet there may be a great deal of change at finer scales. Second, inherent landscape properties, such as topography, soils, and climate, may restrict the magnitude of change making it difficult to evaluate the range of change for unique landscapes across large geographical regions (Hessburg and others 1999). For example, natural fuel barriers, such as scree fields and rocklands, might restrict fire spread in some landscapes, resulting in relatively small changes in landscape composition. The large number of historical observations (1,000 in this study) needed to compute a stable 

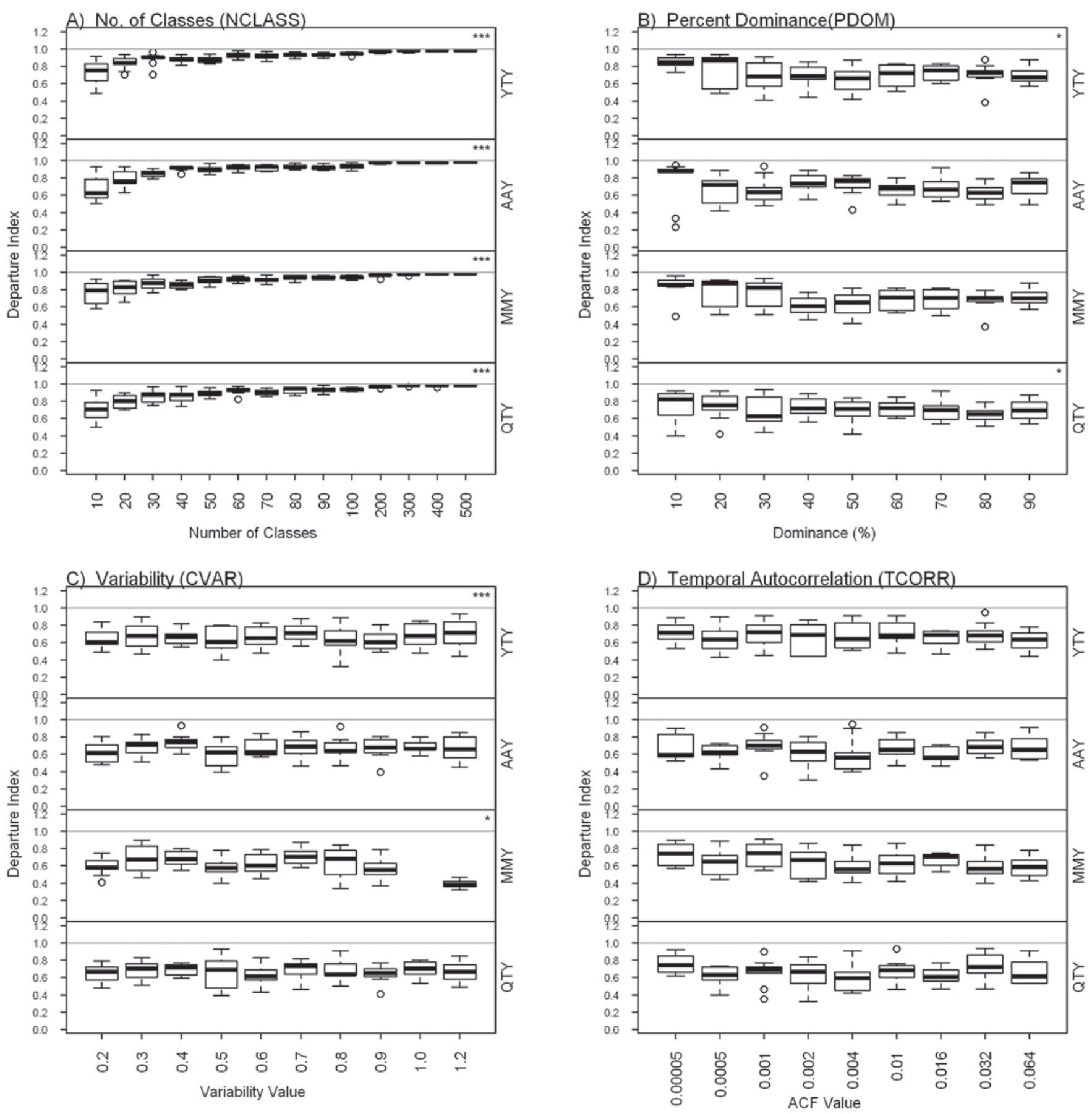

Figure 9-Performance of Sorenson's Index for the four time series synthesis methods when reference landscapes are highly departed from historical conditions (expected departure high; DELTA =1.0). Results for the average departure calculation across all years (YTY) is shown in (a) while the time series synthesis methods reduced the 1,000 historical landscapes into three simplified series: (b) average across all years (AAY), c) a minimum and maximum values across all year, and (c) the $90^{\text {th }}$ percentile value across all years. Box and whisker plots of 10 replicates and the lower boundary of each box is the first quartile (25th percentile), the upper boundary is the third quartile (75th percentile), and the line within the box represents the median of the distribution. The upper and lower whiskers represent the 10th and 90th percentile and the dots below and above the whiskers represent outlying values. Asterisks within each plot indicate significant differences for SI across all treatments at the $0.05\left(^{*}\right), 0.01\left(^{* *}\right)$, and $0.001\left(^{* * *}\right)$ levels. 
Table 2-Qualitative assessment of the performance of the departure indices for each of the four major factors using the numerical codes 1 (poor) to 5 (good) to indicate performance for comparisons of reference to historical time series that are dissimilar (DELTA <0.5) and similar (DELTA >0.5). In this table, DELTA is represented by $\Delta$. The factors are the number of classes (NCLASS), percent dominance (PDOM), class variation (CVAR), and temporal autocorrelation (TCORR).

\begin{tabular}{|c|c|c|c|c|c|c|c|c|c|}
\hline \multirow{3}{*}{$\begin{array}{l}\text { Departure } \\
\text { Index }\end{array}$} & \multicolumn{8}{|c|}{ Factors } & \multirow{3}{*}{ Totals } \\
\hline & \multicolumn{2}{|c|}{ NCLASS } & \multicolumn{2}{|c|}{ PDOM } & \multicolumn{2}{|c|}{ CVAR } & \multicolumn{2}{|c|}{ TCORR } & \\
\hline & $\Delta<0.5$ & $\Delta>0.5$ & $\Delta<0.5$ & $\Delta>0.5$ & $\Delta<0.5$ & $\Delta>0.5$ & $\Delta<0.5$ & $\Delta>0.5$ & \\
\hline $\begin{array}{l}\text { Sorenson's } \\
\text { Index (SI) }\end{array}$ & 5 & 3 & 5 & 3 & 5 & 3 & 5 & 4 & 33 \\
\hline $\begin{array}{l}\text { Morisita's } \\
\text { Index (MI) }\end{array}$ & 1 & 3 & 3 & 2 & 3 & 2 & 3 & 2 & 19 \\
\hline $\begin{array}{l}\text { Similarity } \\
\text { Ratio (SR) }\end{array}$ & 1 & 4 & 3 & 2 & 3 & 2 & 3 & 2 & 20 \\
\hline $\begin{array}{l}\text { Chord } \\
\text { Distance (CD) }\end{array}$ & 1 & 3 & 4 & 2 & 4 & 2 & 3 & 2 & 21 \\
\hline $\begin{array}{l}\text { Euclidean } \\
\text { Distance (ED) }\end{array}$ & 1 & 4 & 4 & 3 & 3 & 3 & 4 & 3 & 25 \\
\hline
\end{tabular}

departure index may restrict the creation of the HRV time series to only using simulation modeling, rather than using historical maps and data. The resolution and extent of the analysis landscape can also influence the range and variability of compositional classes thereby limiting departure estimation (Keane and Karau 2006). It is often difficult to detect departure when landscapes are large and their resolution is fine.

Results of this study illustrate the great need for the development of new, more comprehensive metrics for examining landscape departure (Barrett and others 2006; Steele and others 2006). These new metrics should perform well across the factors used in this study, but they should also contain the following attributes: (1) easily understood and interpreted by land management, (2) statistical tests for significance, (3) utility for other purposes, (4) sensitive to subtle differences across landscapes, (5) contain the ability to incorporate geographic change in departure estimation, and (6) easily computed by hand or with computer. In the meantime, it appears that the community ecology similarity indices, especially SI, can be useful for estimating landscape departure from historical conditions.

\section{References}

Barrett, S. W., DeMeo, T., Jones, J. L., Zeiler, J. D. and Hutter, L. C. 2006. Assessing ecological departure from reference conditions with the Fire Regime Condition Class (FRCC) mapping tool. Pages 575-585 In: P. L. Andrews and B. W. Butler, eds. Fuels management-how to measure success. Proc. RMRS-P-41. Fort Collins, CO: U.S. Department of Agriculture, Forest Service, Rocky Mountain Research Station.

Bloom, S. A. 1981. Similarity indices in community studies: potential pitfalls. Marine Ecology Progress Series 5:125-128.

Bourgeron, P. S. and Jensen, M. E. 1994. An overview of ecological principles for ecosystem management. Pages 45-57 In: M. E. Jensen and P. S. Bourgeron, eds. Ecosystem management: principles and applications. Gen. Tech. Rep. PNW-GTR-318. Portland, OR: U.S. Department of Agriculture, Forest Service, Pacific Northwest Research Station.

Box, G. E. P., Jenkins, G., and Reinsel, G.C. 1990. Time series analysis: Forecasting and control. Holden-Day, Incorporated, New York. 600 p.

Cissel, J. H., Swanson, F. J., McKee, W. A., and Burditt, A. L. 1994. Using the past to plan the future in the Pacific Northwest. Journal of Forestry 92:30-31.

Crow, T. R. and Gustafson, E. J. 1997. Ecosystem management: Managing natural resources in time and space. Pages 215-229 In: K.A. Kohm and J. F. Franklin, eds. Creating forestry for the 21st Century. Washington, DC: Island Press.

Egan, D. and Howell, E. A. 2001. The historical ecology handbook. Washington, DC: Island Press. 457 p.

Faith, D. P., Minchin, P. R., and Beibin, L. 1987. Compositional dissimilarity as a robust measure of ecological distance. Vegetatio 69:57-68. 
Gauch, H. G. 1982. Multivariate analysis in community ecology. New York, NY: Cambridge University Press. 234 p.

Ghent, A. W. 1963. Kendall's "Tua" coefficient as an index of similarity in comparisons of plant or animal communities. The Canadian Entomologist 95:568-575.

Hann, W. J. 2004. Mapping fire regime condition class: A method for watershed and project scale analysis. Pages 22-44 In: Engstrom, R. T., Galley, K. E. M., and De Groot, W. J., eds. 22nd Tall Timbers fire ecology conference: Fire in temperate, boreal, and montane ecosystems. Tallahassee, FL: Tall Timbers Research Station.

Harrod, R. J., McRae, B. H., and Hartl, W. E. 1999. Historical stand reconstruction in ponderosa pine forests to guide silvicultural prescriptions. Forest Ecology and Management 114:433-446.

Hessburg, P. F., Smith, B. G., and Salter, R. B. 1999. Detecting change in forest spatial patterns from reference conditions. Ecological Applications 9:1232-1252.

Holsinger, L., Keane, R. E., Steele, B., Reeves, M. C., and Pratt, S. 2006. Using historical simulations of vegetation to assess departure of current vegetation conditions across large landscapes. Pages 315-367 In: Rollins, M. G. and Frame, C., eds. The LANDFIRE prototype project: Nationally consistent and locally relevant geospatial data for wildland fire management. Gen. Tech. Rep. RMRS-GTR-175. Fort Collins, CO: U.S. Department of Agriculture, Forest Service, Rocky Mountain Research Station.

Horn, H. S. 1966. Measurement of overlap in comparative ecological studies. The American Naturalist 100:419-429.

Huhta, V. 1979. Evaluation of different similarity indices as measures of succession in arthropod communities of the forest floor after clear-cutting. Oecologia 41:11-23.

Kaufmann, M. R., Graham, R. T., Boyce, D. A., Moir, W. H., Perry, L., Reynolds, R. T., Bassett, R. L., Mehlhop, P., Edminster, C. B., Block, W. M., and Corn, P. S. 1994. An ecological basis for ecosystem management. Gen. Tech. Rep. RM-246. Fort Collins, CO: U.S. Department of Agriculture, Forest Service, Rocky Mountain Forest and Range Experiment Station. 22 p.

Keane, R. E., Hessburg, P. F., Landres, P. B. and Swanson, F. J. 2009. A review of the use of historical range and variation (HRV) in landscape management. Forest Ecology and Management 258:1025-1037.

Keane, R. E., Holsinger, L., Parsons, R., and Gray, Kathy. 2008. Climate change effects on historical range of variability of two large landscapes in western Montana, USA. Forest Ecology and Management 254:274-289.

Keane, R. E., Holsinger, L. and Pratt, S. 2006. Simulating historical landscape dynamics using the landscape fire succession model LANDSUM version 4.0. Gen. Tech. Rep. RMRS-GTR-171CD. Fort Collins, CO: U.S. Department of Agriculture, Forest Service, Rocky Mountain Research Station. 73 p.

Keane, R. E., Parsons, R., and Hessburg, P. 2002. Estimating historical range and variation of landscape patch dynamics: Limitations of the simulation approach. Ecological Modelling 151:29-49.

Kobayashi, S. 1987. Heterogeneity Ration: A measure of Beta diversity and its use in community classification. Ecological Research 2:101-111.
Lachowski, H., Maus, P., Golden, M., Johnson, J., Landrum, V., Powell, J., Varner, V., Wirth, T., Gonzales, J., and Bain, S. 1995. Guidelines for the use of digital imagery for vegetation mapping. EM-7140-25. Washington, DC: U.S. Department of Agriculture, Forest Service, Engineering Staff. 29 p.

Landres, P. B., Morgan, Penolope, and Swanson, F. J. 1999. Overview and use of natural variability concepts in managing ecological systems. Ecological Applications 9:1179-1188.

Laughlin, D. C., Bakker, J. D., Stoddard, M. T., Daniels, M. L., Springer, J. D., Gildar, C. N., Green, A. M., and Covington, W. W. 2004. Toward reference conditions: Wildfire effects on flora in an old growth ponderosa pine forest. Forest Ecology and Management 199:137-152.

Ludwig, J. A. and Reynolds, J. F. 1988. Statistical ecology: A primer on methods and computing. New York, NY: John Wiley and Sons. $211 \mathrm{p}$.

Morgan, P., Aplet, G. H., Haufler, J. B., Humphries, H. C., Moore, M. M., and Wilson, W. D. 1994. Historical range of variability: A useful tool for evaluating ecosystem change. Journal of Sustainable Forestry 2:87-111.

Mueller-Dombois, D. and Ellenberg, H. 1974. Aims and methods of vegetation ecology. New York, NY: John Wiley and Sons. $313 \mathrm{p}$

Nonaka, E. and Spies, T. A. 2005. Historical range of variability in landscape structure: a simulation study in Oregon, USA. Ecological Applications 15:1727-1746.

Orloci, L. 1967. An agglomerative method for classification of plant communities. The Journal of Ecology 55:193-206.

Press, W. H., Teukolsky, S. A., Vetterling, W. T. and Flannery, B. P. 2002. Numerical recipes in C++: the art of scientific computing. Cambridge University Press. 533 p.

Steele, B. M., Reddy, S. K. and Keane, R. E. 2006. A methodology for assessing departure of current plant communities from historical conditions over large landscapes. Ecological Modelling 199:53-63.

Swanson, F. J., Jones, J. A., Wallin, D. O. and Cissel, J. H. 1994. Natural variability-implications for ecosystem management. Pages 80-94 In: M. E. Jensen, and P. S. Bourgeron, eds. Volume II: Ecosystem management principles and applications. Eastside forest ecosystem health assessment. Gen. Tech. Rep. PNW-GTR-318. Portland, OR: U.S. Department of Agriculture, Forest Service, Pacific Northwest Research Station.

Swetnam, T. W., Allen, C. D. and Betancourt, J. L. 1999. Applied historical ecology: Using the past to manage for the future. Ecological Applications 9:1189-1206.

Wimberly, M. C., Spies, T. A., Long, C. J. and Whitlock, C. 2000. Simulating historical variability in the amount of old forest in the Oregon Coast Range. Conservation Biology 14:167-180.

Wolda, H. 1981. Similarity, indices, sample size and diversity. Oecologia 50:296-302.

Wong, C. M. and Iverson, K. 2004. Range of natural variability: Applying the concept to forest management in central British Columbia. BC Journal of Ecosystems and Management Extension Note 4:1-56. 




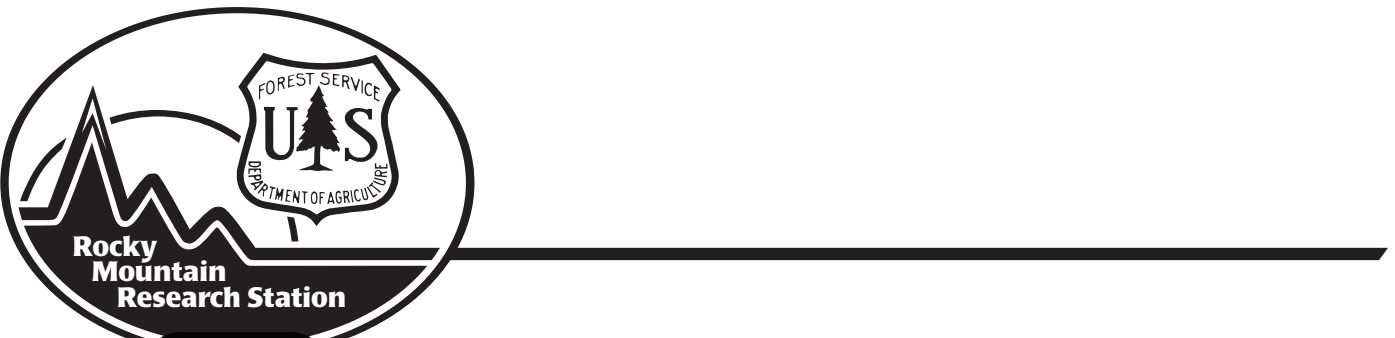

The Rocky Mountain Research Station develops scientific information and technology to improve management, protection, and use of the forests and rangelands. Research is designed to meet the needs of the National Forest managers, Federal and State agencies, public and private organizations, academic institutions, industry, and individuals. Studies accelerate solutions to problems involving ecosystems, range, forests, water, recreation, fire, resource inventory, land reclamation, community sustainability, forest engineering technology, multiple use economics, wildlife and fish habitat, and forest insects and diseases. Studies are conducted cooperatively, and applications may be found worldwide.

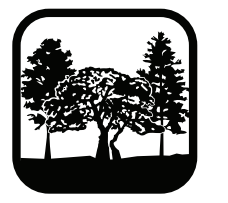

\author{
Station Headquarters \\ Rocky Mountain Research Station \\ 240 W Prospect Road \\ Fort Collins, CO 80526 \\ (970) 498-1100
}
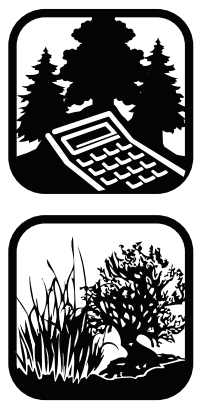

Research Locations

Flagstaff, Arizona

Fort Collins, Colorado

Boise, Idaho

Moscow, Idaho

Bozeman, Montana

Missoula, Montana
Reno, Nevada

Albuquerque, New Mexico

Rapid City, South Dakota

Logan, Utah

Ogden, Utah

Provo, Utah

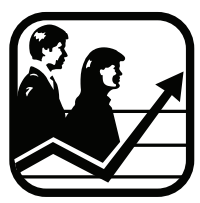

The U.S. Department of Agriculture (USDA) prohibits discrimination in all its programs and activities on the basis of race, color, national origin, age, disability, and where applicable, sex, marital status, familial status, parental status, religion, sexual orientation, genetic information, political beliefs, reprisal, or because all or part of an individual's income is derived from any public assistance program. (Not all prohibited bases apply to all programs.) Persons with disabilities who require alternative means for communication of program information (Braille, large print, audiotape, etc.) should contact USDA's TARGET Center at (202) 720-2600 (voice and TDD). To file a complaint of discrimination, write to USDA, Director, Office of Civil Rights, 1400 Independence Avenue, S.W., Washington, DC 20250-9410, or call (800) 795-3272 (voice) or (202) 720-6382 (TDD). USDA is an equal opportunity provider and employer. 